\title{
CAN WE CONTROL THE CARBON DIOXIDE IN THE ATMOSPHERE?
}

\author{
FREEMAN J. DYSON ${ }^{\dagger}$ \\ Institute for Energy Analysis, Oak Ridge, TN 37830, U.S.A.
}

(Received 26 July 1976)

\begin{abstract}
The carbon dioxide generated by burning fossil fuels can theoretically be controlled by growing trees. Quantitative estimates are made of the size and cost of a plant-growing program designed to halt the increase of carbon dioxide in the atmosphere.
\end{abstract}

STATEMENT OF THE PROBLEM

At present (1976) the $\mathrm{CO}_{2}$ in the atmosphere contains $7 \times 10^{11}$ tons of carbon.' The burning of fossil fuels is adding to the atmosphere $5 \times 10^{9}$ tons of carbon per $\mathrm{yr}^{2}{ }^{2}$ Of this amount, only $2.5 \times 10^{9}$ tons per $\mathrm{yr}$ is appearing as net increase of atmospheric $\mathrm{CO}_{2}$. The remaining $2.5 \times 10^{9}$ tons per yr is absorbed by the ocean and the biosphere. How much goes into the ocean and how much into the biosphere is still a matter of conjecture. ${ }^{3}$ The present carbon content of the biosphere is only roughly known. Estimated values, ${ }^{4}$ probably correct to within a factor of 2, are:

Peat and Humus: $10^{12}$ tons carbon,

Long-lived vegetation (trees): $6 \times 10^{11}$ tons,

Rapid exchange pools (leaves, roots, litter, invertebrates) $-\left(50 \%\right.$ alive, $50 \%$ dead): $2 \times 10^{11}$ tons.

The carbon in living plants is approximately equal to the total atmospheric carbon. Moreover, the net quantity of carbon photosynthetically transferred (gross photosynthesis minus respiration) from the atmosphere to the biosphere is approx. ${ }^{5} 5 \times 10^{10}$ tons carbon per yr, about 20 times the annual increase of atmospheric carbon. The net photosynthesis is almost exactly balanced by the processes of decay, grazing and burning which convert carbon to $\mathrm{CO}_{2}$ and return it to the atmosphere.

There are several other human activities which may have effects on atmospheric $\mathrm{CO}_{2}$ comparable with the effects of fossil fuel burning, but which are much more difficult to measure. One such activity is the clearing and replacement of forests by cropland and pasture. If $1 \%$ of the total tropical forest is being destroyed each year, (and nobody knows for sure the extent of such clearing), then about $1.2 \times 10^{9}$ tons of carbon per $\mathrm{yr}^{5}$ are added to the atmosphere as a result. On the other hand, there is evidence ${ }^{6}$ that modern methods of agriculture, with heavy use of fertilizer and plowing back of crop residues into the ground, may produce substantial increases in the carbon content of humus in agricultural land. A third human activity, which is also subtracting carbon from the atmosphere, is the eutrophication of lakes and estuaries and the resultant build-up of organic sediments. Finally, there is the very complicated question of the possible increase of the carbon content of the biosphere ${ }^{6}$ due to increased rates of photosynthesis in response to the growing abundance of $\mathrm{CO}_{2}$ in the atmosphere. The magnitude of this negative feed-back effect of atmospheric $\mathrm{CO}_{2}$ upon itself depends on many ecological interactions which have yet to be disentangled. The effect could be negligibly small, or it could be as large as $3 \times 10^{9}$ tons of carbon per yr. ${ }^{5}$ In summary, there is insufficient evidence to decide whether the carbon content of the biosphere has decreased, increased or remained stationary in response to the manifold human activities of recent decades.?

There exists a huge literature ${ }^{8}$ attempting to assess or to prognosticate the effects of the increasing atmospheric $\mathrm{CO}_{2}$ on the climate of the earth. Such attempts are useful and necessary, but they run into formidable technical difficulties. Even the mean global temperature rise caused

†Present address: Institute for Advanced Study, Princeton, NJ 08540, U.S.A. 
by a given quantity of $\mathrm{CO}_{2}$ is subject to great uncertainty, and the effects of $\mathrm{CO}_{2}$ on local and time-variable phenomena (which may be crucially important to agriculture and other human activities) are more uncertain still. It is possible that the rise in $\mathrm{CO}_{2}$ will be on balance beneficial to mankind, especially in reducing climatic extremes in very cold and very dry regions. The prevailing opinion ${ }^{10}$ is that the dangers greatly outweigh the benefits. But in spite of various dire warnings, "it seems inevitable that we shall continue for many decades to burn fossil fuels and to increase the level of atmospheric $\mathrm{CO}_{2}$, without knowing with any degree of certainty the consequences of our actions.

The time is now ripe to ask a different question. ${ }^{12}$ Suppose that with the rising level of $\mathrm{CO}_{2}$ we run into an acute ecological disaster. Would it then be possible for us to halt or reverse the rise in $\mathrm{CO}_{2}$ within a few years by means less drastic than the shutdown of industrial civilization? I shall tentatively answer this question in the affirmative. Since the annual photosynthetic turnover is 20 times larger than the annual increase in atmospheric $\mathrm{CO}_{2}$, it should be possible in case of a world-wide emergency to plant enough trees and other fast-growing plants to absorb the excess $\mathrm{CO}_{2}$ and bring the annual increase to a halt. The purpose of the present paper is to estimate roughly the size, cost and feasibility of such an emergency plant-growing program.

It is important to distinguish between long-term and short-term responses to a threat of catastrophe caused by $\mathrm{CO}_{2}$. The long-term response, if such a catastrophe becomes imminent, must be to stop burning fossil fuels and convert our industry to renewable photosynthetic fuels, nuclear fuels, geothermal heat and direct solar-energy conversion. But a world-wide shift from fossil to non-fossil fuels could not be carried out in a few years. A beginning could be made right away, for example by converting coal-fired power-stations to saw-dust and low-grade timber. If suitable preparations were made in advance, a substantial decrease in fossil-fuel burning might be achieved in 10 or $20 \mathrm{yr}$, and the transition to renewable fuels might be essentially complete within $50 \mathrm{yr}$. But this response might well be too slow to avoid a $\mathrm{CO}_{2}$ disaster. An emergency plant-growing program would provide the necessary short-term response to hold the $\mathrm{CO}_{2}$ at bay while the shift away from fossil fuels is being implemented. It is essential to the purpose of the program that the newly grown trees and plants should not be used as fuel except in places where they can directly replace fossil fuels. The newly grown vegetation is to be thought of as a "carbon bank", holding carbon in reserve until we have built the appropriate industrial machinery to use it safely. There are two chief ways in which carbon can be transferred from the atmosphere into long-term storage, either by growing long-lived trees which are left unharvested, or by growing short-lived plants which are converted to humus or allowed to accumulate in artificial peat-bogs. Either method requires large areas of land. Some of the planting may be done on land which is at present unproductive, but much of it may be done on existing agricultural or productive forest land with some changes in the management of crops and fertilizers. There is no necessary incompatibility between increased yields of food and forest products and increased inventories of carbon in trees and humus.

It is highly unlikely that the particular emergency program here proposed will ever be implemented. My discussion of it is enormously oversimplified. The purpose of this paper is to begin a process of mental preparation which may enable us to have realistic plans ready if ever the danger of catastrophe from $\mathrm{CO}_{2}$ accumulation becomes acute. To have plans ready is a form of life insurance, valuable even if the threatened catastrophe never happens. And there are many other useful purposes which a global reserve stock of organic materials might serve, quite apart from its use as a buffer against atmospheric $\mathrm{CO}_{2}$.

My proposal for purging $\mathrm{CO}_{2}$ from the atmosphere biologically, and Marchetti's proposal ${ }^{12}$ for purging $\mathrm{CO}_{2}$ from fossil-fuel plant effluents physically with subsequent disposal of liquefied $\mathrm{CO}_{2}$ in the deep ocean, are not mutually exclusive. Both may be useful, and each may have advantages at certain places and times. A comparison of costs and time-scales between the two proposals will not be attempted here.

QUANTITATIVE ESTIMATES

We wish to be prepared to withdraw from the atmosphere a quantity of carbon comparable with the current rate of growth of atmospheric $\mathrm{CO}_{2}$. If the withdrawal were to begin now (1976), the quantity would be $2.5 \times 10^{9}$ tons of carbon per yr. In the future the consumption of fossil fuels will rise, and the necessary withdrawal rate will rise to several times the present value. Current 
projections ${ }^{13}$ indicate that in the year 2000 the rate of fossil fuel use is likely to be between 2 and 4 times the present rate. The required rate of withdrawal between now and the year 2000 will therefore lie in the range from $2.5 \times 10^{9}$ to $10^{10}$ tons of carbon per yr. I take the value $5 \times 10^{9}$ tons per $y r$ as illustrative of the magnitude of the problem that would arise if the withdrawal plan had to be implemented at some unspecified time within the next $25 \mathrm{yr}$. Beyond the year 2000 the problem may or may not become more severe, depending on a multitude of unpredictable contingencies.

Two promising candidates ${ }^{14}$ for rapid-growth plantations are trees and swamp-plants. A great variety of trees could be grown on marginal land in various parts of the world. As an example of a tree-crop suited to the Southeastern United States, I consider American Sycamore as grown experimentally by the School of Forest Resources of the University of Georgia. ${ }^{15}$ This yields about 750 tons of carbon per $\mathrm{km}^{2}$ per yr ( 3 tons per acre per $\mathrm{yr}$ ). We do not know how much vegetation was destroyed in the clearing of the land before the trees were planted, nor do we know the effect of the plantation on the inventory of carbon in humus in the soil. If we assume that we can achieve a net increase of fixed carbon of 3 tons per acre per $y r$, then we should need about $7 \times 10^{6} \mathrm{~km}^{2}$ of land to counter the atmospheric $\mathrm{CO}_{2}$ growth with this particular crop. Of course, the area suitable for American Sycamore plantation is much less than $7 \times 10^{6} \mathrm{~km}^{2}$. The area of the U.S. suitable for some kind of tree plantation is estimated ${ }^{16}$ to be about $7 \times 10^{5} \mathrm{~km}^{2}$. This is the area that has at least $20 \mathrm{in}$. of annual rainfall and is at present unproductive. Much of the area is already covered with low-grade forest, and detailed surveys would be required to determine what fraction of it should be replanted and what fraction should be merely fertilized and managed so as to promote rapid growth. The U.S. could thus provide about one tenth of the required growth of trees. The total area of forest in the world is about $5 \times 10^{7} \mathrm{~km}^{2}$. To absorb $5 \times 10^{9}$ tons of carbon per yr from the atmosphere, it would be necessary to achieve an average world-wide increase in long-term forest growth of 0.4 ton of carbon per acre per yr, or a growth of 3 tons per acre per yr on one seventh of the area. The additional growth should be in species that live $50 \mathrm{yr}$ or longer, so that their carbon is not returned to the atmosphere by decay before it can be safely harvested. Most commercial species are sufficiently long-lived for this purpose.

An alternative to tree-planting is the intensive cultivation of aquatic plants. Water hyacinths are especially interesting ${ }^{17}$ because of their rapid growth and hardiness. They yield about 6000 tons of carbon per $\mathrm{km}^{2}$ per yr (24 tons per acre per yr), about 8 times as much as American Sycamore. They can only be grown on flooded land with abundant fresh water, or in canals or ponds. To fix $5 \times 10^{9}$ tons of carbon per yr we would need an area of $8 \times 10^{5} \mathrm{~km}^{2}$. The total area of tropical swampland that might with some adaptation be suitable for water hyacinths ${ }^{14}$ is about $25 \times 10^{5} \mathrm{~km}^{2}$. Most of this land is in South America, Africa and South-East Asia. The U.S. has only $2 \times 10^{5} \mathrm{~km}^{2}$, and the greater part of this is the Mississippi floodplain which has long ago been drained and used for farming. Still there is enough wetland left in the U.S. to make a non-negligible contribution to the amelioration of the $\mathrm{CO}_{2}$ problem.

The intensive cultivation of water-hyacinths has been proposed" as a source of pipeline-quality gas (essentially pure methane) obtained by digesting the plants anaerobically in large fermentation tanks. If the plants are to be used as a sink for atmospheric $\mathrm{CO}_{2}$, it is essential to store them after harvesting in a semi-permanent fashion so that digestion to methane does not occur. We would have to duplicate artificially the conditions of acidity and sterility that cause vegetation in natural peat-bogs to form peat rather than methane. Extensive experimentation is required to find out whether artificial peat-bogs on the required scale are either feasible or environmentally acceptable.

There are many types of soft plant other than water-hyacinth which could be used to build up carbon reserves in the form of humus, either in cropland or in natural swamps and wetland. Some of these plants would, like sugar-cane, have commercial value as food-crops or energy-crops ${ }^{18}$ in addition to their value as carbon-fixers. I do not attempt here any assessment of the various possible alternatives.

One of the major problems in building up a "carbon bank", either with trees or with soft plants, is that the vegetation does not consist of pure cellulose but also incorporates substantial quantities of the elements $N, P$ and $K$. In most parts of the world, natural forests grow without artificial fertilization, but any plan for forced rapid growth of trees or plants will require the use of fertilizers. To estimate the magnitude of this problem, I use the input-output data from the 
experimental planting of American Sycamore seedlings in Georgia. ${ }^{15}$ For a 2 yr cycle yielding a crop of 13.4 tons dry weight per acre (this means about 6 tons of fixed carbon), the quantities of fertilizer input were $215 \mathrm{lb} \mathrm{N}, 20 \mathrm{lb} P$ and $40 \mathrm{lb} K$; and the quantities of these elements in the harvested crop were $51 \mathrm{lb} N, 5 \mathrm{lb} P$ and $19 \mathrm{lb} K$. Roughly speaking, these input quantities set an upper bound, and the output quantities set a lower bound to the quantities of fertilizer required for an intensive rapid-growth program. The larger the area planted, the less need there would be for heavy fertilization. If we use the output quantities to estimate the requirements, then for fixing $5 \times 10^{9}$ tons of carbon per yr we would need to consume fertilizers at an annual rate of $2 \times 10^{7}$ tons $N, 7 \times 10^{6}$ tons $\mathrm{P}_{2} \mathrm{O}_{5}$ and $10^{7}$ tons $\mathrm{K}_{2} \mathrm{O}$. These numbers are about one half of the figures ${ }^{19}$ for the total world use of fertilizers in the year 1973 . The availability of fertilizers will probably be the critical factor limiting the scale and speed of carbon fixation.

The uncertainties in estimates of financial costs are even greater than those in estimates of fertilizer requirements. One proposa ${ }^{16}$ for the large-scale planting and harvesting of tree crops for energy generation estimates the cost at $\$ 140$ (1975 dollars) per acre for land clearance and planting. If each acre thereafter fixes 3 tons of carbon per yr, we would need to spend $\$ 2 \times 10^{11}$ (spread over several years) to establish plantations fixing $5 \times 10^{9}$ tons of carbon per yr. To this must be added the continuing cost of fertilizer ${ }^{20}$ which will be of the order of $\$ 12 \times 10^{9}$ per yr. Such costs are not unreasonable for a world-wide effort in response to a dire global emergency. The costs could perhaps be lower if most of the planting were done by labor-intensive methods in countries where labor is cheap.

Another way of counting the costs ${ }^{21}$ is to suppose that every burner of fossil fuel is taxed at a rate high enough to pay for his share of the operation of purging $\mathrm{CO}_{2}$ from the atmosphere. Since I have assumed a purging of $5 \times 10^{9}$ tons of carbon per yr, which is twice the present rate of growth of atmospheric carbon, it is consistent to assume a world consumption of fossil fuels at twice the present rate. We have then a consumption of $1.2 \times 10^{14} \mathrm{kWh}$ (thermal) per yr of fossil fuel, to be taxed so as to yield $\$ 25 \times 10^{9}$ per yr for the annual cost of fertilizer plus the capital cost of plantations at $12 \%$ interest. The tax rate is 0.021 cents per $\mathrm{kWh}$, or 6 cents per million Btu. My cost estimates are exceedingly crude, and I have not attempted to take into account the cost of land used for plantations. Still it is encouraging that the estimated costs, when converted into a tax on polluters of the atmosphere, turn out to be easily supportable.

\section{CONCLUSIONS}

There seems to be no law of physics or of ecology that would prevent us from taking action to halt or reverse the growth of atmospheric $\mathrm{CO}_{2}$ within a few years if this should become necessary. Two methods of withdrawing carbon from the atmosphere have been described, among many possible alternatives. One is to plant fast-growing trees on a massive scale on marginal land; the other is to grow and harvest swamp-plants and convert them into humus or peat. The possible scale and speed of these operations appear to be limited by the availability of fertilizer rather than by land or financial costs. The establishment of such a "carbon bank" in the form of trees or peat is not to be regarded as a permanent solution of the $\mathrm{CO}_{2}$ problem. It is a stop-gap measure to hold the atmospheric $\mathrm{CO}_{2}$ level down for a few decades and buy time in which a permanent shift from reliance on fossil fuels to renewable photosynthetic (or nuclear) fuels can be completed. ${ }^{22}$

Acknowledgements -I thank Dr. A. M. Weinberg for the hospitality of the Institute for Energy Analysis, Oak Ridge Associated Universities, where this work was done. I thank Drs. A. M. Weinberg, R. M. Rotty, A. D. Poole and D. R. Weinberg for helpful discussions. This paper is Occasional Paper IEA (0)-76-4 of the Institute for Energy Analysis. I am alone responsible for the views expressed in it.

\section{REFERENCES} 1. C. Baes, H. Goeller, J. Olson and R. M. Rotty, The global carbon dioxide problem. Report ORNL-5194, Dak Ridge National
Laboratory, 1976 .

2. R. M. Rotty, Global carbon dioxide production from fossil fuels and cement. IEA report prepared for ONR Conference on the Fate of Fossil Fuel Carbon Dioxide, Honolulu, 1976.

3. R. Bacastow and C. D. Keeling, Atmospheric carbon dioxide and radio-carbon in the natural carbon cycle-II. Changes from 1700 to $2070 \mathrm{AD}$ as deduced from a geochemical model. Proc. 24th Brookhaven Symposium in Biology (Edited by G. M. Woodwell and E. V. Pecan). USAEC, 1973.

4. C. Baes, H. Goeller, I. Olson and R. M. Rotty, Ref. 1, Section 2.2.2. 
5. C. Baes, H. Goeller, J. Olson and R. M. Rotty, Ref. 1, Section 2.3.2.

6. E. Lemon. The land's response to more carbon dioxide. U.S. Agricultural Research Service, Department of Agronomy Series Paper No. 1156, presented at ONR Conference on the Fate of Fossil Fuel Carbon Dioxide. Honolulu. 1976.

7. C. Hall, C. Ekdahl and D. Wartenberg, Nature 255, 136 (1975).

8. For example. S. Manabe and R. T. Wetherald, J. Atmos. Sci. 32, 3 (1975)

9. S. H. Schneider, J. Atmos. Sci. 32. 2060 (1975).

10. R. M. Rotty, Energy and the climate. IAE Technical Memorandum (M)-75-3, 1975.

11. H. A. Wilcox, Hot-House Earth. Praeger, New York (1975).

12. The same question has also been asked by $\mathrm{C}$. Marchetti, On geo-engineering and the $\mathrm{CO}_{2}$ problem. International Institute for Applied Systems Analysis, RM-76-17, 1976: and by W. D. Nordhaus. Can we control carbon dioxide? IIASA Internal Paper, WP-75-63 (June 1975).

13. C. Baes, H. Goeller, J. Olson and R. M. Rotty, Ref. 1, Section 2.4.

14. A. D. Poole, Biological energy sources. Unpublished, Cambridge (1974).

15. K. Steinbeck and C. L. Brown. Yield and utilization of hardwood fiber grown on short rotations. Proc. Applied Polymer Symposium No. 28. Wiley. New York (1975).

16. M. D. Frazer, J. F. Henry and C. W. Vail, Proc. Symposium on Clean Fuels, pp. 371-395. Institute of Gas Technology (1976).

17. R. P. Lecuyer and J. H. Marten, Proc. Symposium on Clean Fuels, pp. 267-286. Institute of (jas Technology (1976): A. D. Poole and R. H. Williams. Bull. Atom. Scientists 32(5), 28 (1976).

18. J. A. Alich and R. E. Inman, Energy 1, 53 (1976).

19. United States and world fertilizer outlook, 1974 and 1980. U.S. Department of Agriculture Economic Research Service. Washington, D. C.. Feb. 1974. The quantity of $\mathrm{P}_{2} \mathrm{O}_{5}$ used in 1973 was almost four times $7 \times 10^{6}$ tons.

20. I assume a consumption of $5 \times 10^{7}$ tons per year of fertilizer at an average price of $\$ 250$ per ton, which is below the 1974 price but above the 1975 price. See A. D. Poole, The fertilizer bank. IEA Occasional Paper (0)-76-2, (1976), and R. B. Reidinger, World fertilizer review and prospects to 1980-81. U.S. Department of Agriculture Economic Research Service, Foreign Agriculture Economic Report No. 115, (1976). Of course there is no reason to believe that an additional $5 \times 10^{7}$ tons per yr of fertilizers could be produced without a substantial rise in prices.

21 Suggested by Dr. D. Weinberg. Private communication. 